\title{
Web-Based Remote Control Laboratory Using a Greenhouse Scale Model
}

\author{
J. L. GUZMÁN, ${ }^{1}$ M. BERENGUEL, ${ }^{1}$ F. RODRÍGUEZ, ${ }^{1}$ S. DORMIDO ${ }^{2}$ \\ ${ }^{1}$ Dpto. de Lenguajes y Computación, Área de Ingeniería de Sistemas y Automática, Universidad de Almería, Spain \\ ${ }^{2}$ Dpto. de Informática y Automática, UNED, Spain
}

Received 4 September 2003; accepted 14 November 2004

\begin{abstract}
Greenhouse automation is one of the main advances in modern agriculture, this subject being included in many agricultural engineering and applied control curricula. This study presents the development of a web-based remote control laboratory using a greenhouse scale model for teaching greenhouse climate control techniques using different hardware and software platforms. (๑) 2005 Wiley Periodicals, Inc. Comput Appl Eng Educ 13: 111-124, 2005; Published online in Wiley InterScience (www.interscience.wiley.com); DOI 10.1002/cae.20035
\end{abstract}

Keywords: control education; remote laboratory; greenhouse climate control

\section{INTRODUCTION}

In the last decades our society has been itself coiled by the vertiginous advances undergone in the information and communication technologies (ICT), giving rise to innumerable changes in enterprise, cultural, social, and educational fields. These advances have produced a creation of new techniques and methods opening a wide range of possibilities not only in the industrial area (remote control, remote management, flexible

Correspondence to J. L. Guzmán (joguzman@ual.es).

Contract grant sponsor: CICYT; contract grant numbers: QUI99-0663-C02-02, DPI2001-1012， DPI2001-2380-C02-02, DPI2002-04375-C03-03.

(c) 2005 Wiley Periodicals Inc. timetable,...), but also in the educational field (distance education, interactive information, remote, and virtual laboratories, ...). The rapid development of Internet and distributed computing facilitates the development of feasible and cost-effective solutions.

The main advantages of the ICT are related with teleaccess, teleoperation, and telecontrol. Until recently, the exchange of information was done using local networks; several reasons being information safety, narrow bandwidths, limited tools for the exchange of information, .... Thanks to the advances in Internet technologies, a new method, teleaccess, for accessing the information has been introduced which provides a way to safely access to the information from any part of the world without temporal constraints. Both in the industrial and research/educational fields high costs are often related to the restricted use of 
(usually expensive) systems with usage-time constraints or to the displacements required to control them. With teleoperation (extension of sensorial capabilities and human skill to the remote place) and telecontrol (specific part of teleoperation whose goal is to send commands to the actuators) technologies it is possible to control systems remotely through Internet, thus helping to diminish displacement costs and allowing to extend the use of time-limited resources or equipment.

In the educational field, new teaching methods have been introduced allowing the teachers to find innovative techniques to enhance the students' motivation and improve their education: multimedia tools, hypertext systems, interactive systems, information exchange between teacher and student through internet, information access from any part of the world without temporal constraints,... where the biggest revolution has been produced by the World Wide Web. All these advantages are useful for subjects without a strong practical component, but there exist other subjects with strong experimental contents that require a new element allowing the students to apply the acquired knowledge. Traditionally this element has been a local simulation tool or a local laboratory, this being used by the students to perform several practical exercises using real systems but with space and time constraints. Nowadays, thanks to advances in the ICT, especially in Internet technologies, the laboratory environment can be transformed into distance education. By this, two new concepts have appeared within the distance education framework, virtual laboratories and remote laboratories. The first of them is a new kind of simulation tool much more powerful than the traditional ones, allowing the simultaneous use of remote simulation modules by the students. On the other hand, remote laboratories allow the students to perform the main laboratory activities remotely, without requiring the presence of the students at the place where the hardware is placed, in such a way that the students can control and monitor physical devices 24 hours a day at any time and anywhere, interacting with the teacher without having a move to the university. Remote labs help the students to put into practice what they have learned by remotely accessing real systems.

Greenhouse automation is one of the main advances in modern agriculture, this subject being included in many agricultural engineering and applied control curricula. This study presents the development of a web-based remote control laboratory using a greenhouse scale model for teaching greenhouse climate control techniques using different hardware and software platforms. This system can also be used to remotely control industrial greenhouses via Web. The architecture of the system and the implemented control algorithms, including illustrative examples, are briefly explained.

This study is organized as follows: after presenting a review of the works related to that presented in this study, some considerations would be commented regarding distance education and telelaboratories. The proposed control architecture and development steps for a remote lab using a greenhouse scale model are explained. Finally, a section enumerating the steps required to perform a practical test are included, followed by some conclusions.

\section{BACKGROUND}

Many works related with distance education and telelaboratories have been performed. The ICT influence in control learning is treated in detail in References [1-3]. Regarding remote labs, different applications can be found in the literature for several disciplines and using different tools. Some interesting examples can be found in References [4-9]. In Reference [4], a remote Simulink block is developed for reading real values of a remote plant. Reference [5] describes a remote laboratory where it is possible to control a robot manipulator, a tank process, and a toy-helicopter; in Reference [6], a remote lab for controlling an AC motor has been developed using Simulink, LabVIEW, and Java. Reference [7] presents five different experiments that can be controlled remotely: DC motor velocity, DC motor position, a tank level, a magnetic levitation system, and a toyhelicopter. In References [8,9], remote robotic laboratories are shown for working with a manipulator robot and mobile robots, respectively.

In the field of virtual labs, many different applications can be found in the literature related to different disciplines: civil, mechanical, and material science engineering [10-15], electrical engineering [16], robotics and manufacturing [17], control engineering [18], etc. In Reference [10], a web-based virtual lab which allows to develop 2-D structures remotely is presented; Reference [11] presents three web-based virtual labs for studying, analyzing, and understanding concrete structures; Reference [12] shows a web-based virtual environment to perform common activities of a CAD tool; References [13,14] present the development and use of a web-based tool for performing simulations using MATLAB remotely; Reference [15] introduces a virtual course aimed at improving the understanding of metallurgy theory using interactive activities and animations; Reference 
[16] presents a summary of the different tools that can be used in laboratory courses and their applications to control a three-phase induction motor; Reference [17] shows a web-based virtual mini-manufacturing corporation to help the students to understand the different activities that are performed in a real manufacturing; in Reference [18], a virtual laboratory is presented with two heat exchangers in series for teaching and training industrial personnel. In Reference [19], a virtual lab is described where several plants are simulated using VRML. In Reference [20], a virtual and a remote laboratory is presented where it is possible to work with three experiments: a heat exchanger, a tank level, and a distillation column. First it is possible to perform the control in simulation and after that to perform it using real plants.

Regarding the software used in this study References [21-24], describe the use of LabVIEW in distance education and telelaboratories.

As it has been pointed out, different professional associations and universities are nowadays supporting the inclusion of control aspects in the education of modern agricultural engineers. For instance, AFANet (thematic network within the framework of the Socrates programme of the UE) and University Studies of Agricultural Engineering in Europe (USAEE) network have performed a study trying to unify the studies of Agricultural Engineering in Europe. One of the aspects treated in this study is the convenience of including subjects from classical and modern engineering studies in the studies of Agricultural Engineering, such as electronics, systems engineering, control systems design, modern control techniques (predictive and optimal control), robotics, etc.

In the field of the application of remote control to agricultural engineering few references can be found in the literature. In Reference [25], a local greenhouse scale model can be found to perform experiments in a traditional local laboratory. In References [26,27], the design and implementation of an integrated network that links several communication platforms for allowing the control of a greenhouse remotely is described. In Reference [28], an application of remote control of greenhouse climate is presented.

\section{DISTANCE EDUCATION AND TELELABORATORIES}

With distance education the overcrowding in the classrooms is reduced. It also involves important economic improvements. On one hand teachers and students do not have to move always to the university, and on the other hand there are many infrastructure savings because the classrooms do not need to be so well equipped as before. This kind of education helps students to be more self-sufficient, which is very important in becoming an engineer. However, the tutor must continue with a direct and exhaustive follow-up of the student, just like the traditional education [3].

All these advantages will be of in vain if they are not used effectively. A wrong use of these emerging methods can make students even more passive than they are in the normal classroom environment. The student assumes a central role as the active architect of his/her knowledge and skills, rather than passively absorbing information delivered by the teacher. The WWW and other information sources cannot be a solution to educational needs unless the creative component is included [1]. One new concept related with distance education is just-in-time teaching (JiTT). JiTT is a method that exploits an interaction between web-based study and an active learner classroom. It is a strategy that combines use of the web with a collaborative learning environment to improve student learning and attitudes toward various content areas [29]. These are very powerful teaching methods when used in subjects without a strong practical component. There exist several disciplines such as automatic control, which have an important practical content, requiring experimentation environments that allow the students to apply the knowledge acquired, using for these real systems or simulated ones.

There are several kinds of experimentation environments. These are classified from the point of view of the students using two criteria [30]:

- The way of accessing the resources: local access versus remote access.

- The nature of the physical system: simulated models versus real plants.

Using these criteria four types of experimentation environments can be obtained: local access-real resource, local access-simulated resource, remote access-real resource, and remote access-simulated resource. This classification is found in more detail in References [1] and [30]. These new kind of laboratories must have a set of properties (realism, simplicity, availability, etc.) to avoid a decrease in the students motivation, feeling of loneliness, etc. [30].

In this study, a remote access-real resource laboratory has been developed, where the user operates and controls in a remote way a real plant (greenhouse) through the Internet. 


\section{CONTROL ARCHITECTURE AND DEVELOPMENT STEPS}

The first step in the development of the remote lab was to develop a system that is able to control greenhouse climatic conditions locally and irrigation by using two different hardware platforms (PC-computer and/or PLC) to account for the different options currently taught at the universities and installed in the field of industrial intensive agriculture. LabVIEW 6.1 from National Instruments has been selected as SCADA system, as it constitutes an easy to use graphical programming environment based on the concept of data flow programming oriented to the instrumentation field and allowing to export the application for remote control purposes [22,23]. The architecture of the system is shown in Figure 1. The system has been incrementally developed in several steps:

- Study of the optimal climatic and irrigation conditions

- Development of greenhouse climate and irrigation control algorithms
- Implementation of the algorithms in a PLC

- Implementation of the algorithms in a PC

- Development of a tool for combining and selecting the control platform

- Development of the remote application and incorporation to a website

\section{Greenhouse Climate and Irrigation Control Algorithms}

The main goal of greenhouse crop production is to maximize understanding of benefits such as the difference between the incomes coming from the sale of the final production and its associate costs. To account for this objective it is thus necessary to control the greenhouse climate, irrigation, and fertilization. The main methods of controlling the greenhouse climate are by using ventilation and heating to modify inside temperature and humidity conditions, shading, and artificial light to change internal radiation, $\mathrm{CO}_{2}$ injection to influence photosynthesis and fogging/misting for humidity enrichment. Figure 2 shows the elements that constitute the greenhouse

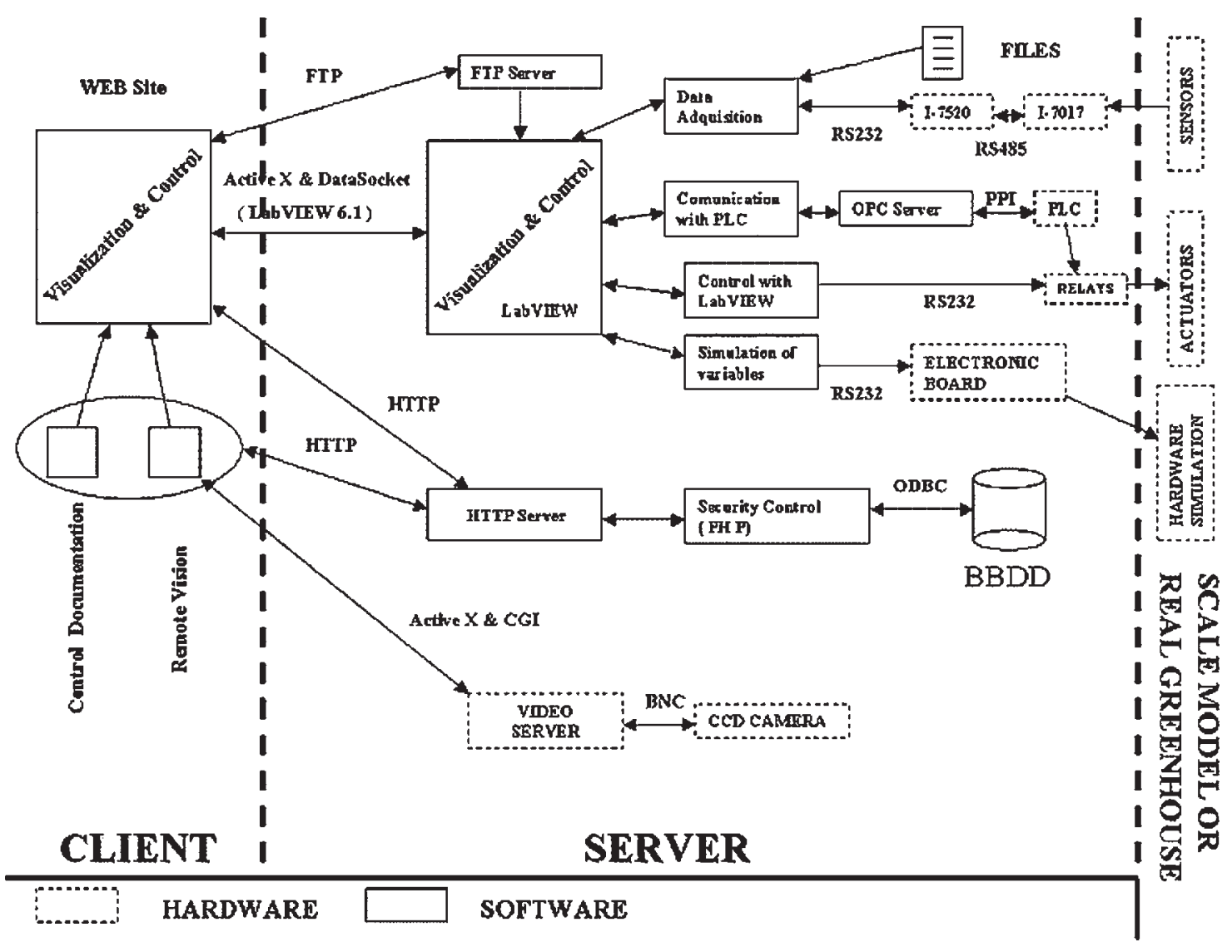

Figure 1 Remote control architecture. 


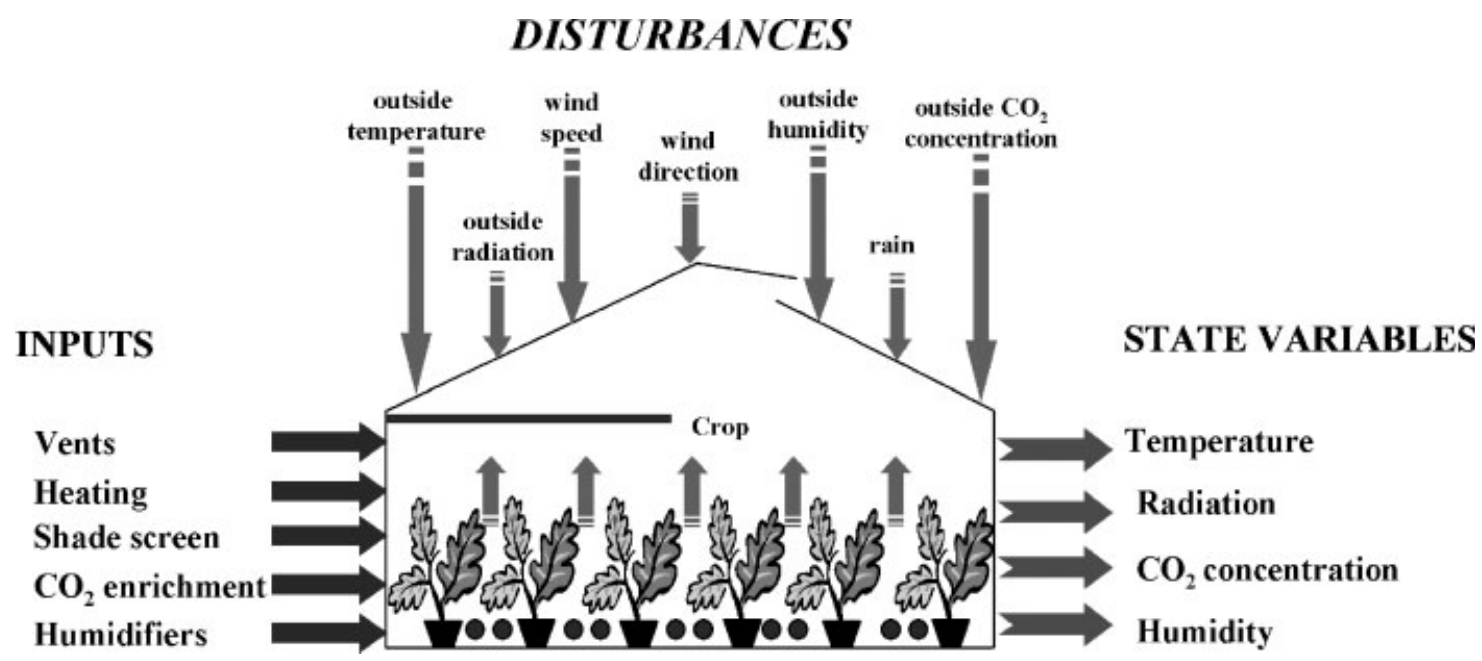

Figure 2 Input, state, and disturbance variables in greenhouse climate control.

climate control system and Figure 3 shows different views of the sensors and actuators placed at a real greenhouse.

Different classical and advanced control techniques have been applied to this problem during the last years [31,32], this includes PID control, cascade control, feedforward control, model predictive control, adaptive control, etc. At present, classical control techniques are those implemented in mostly automated greenhouses and thus taught at universities. In

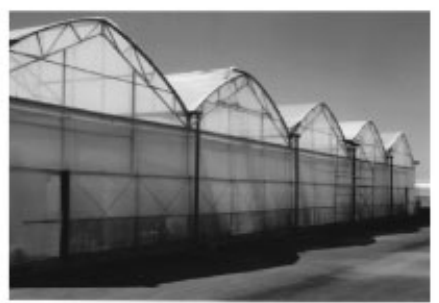

outside structure

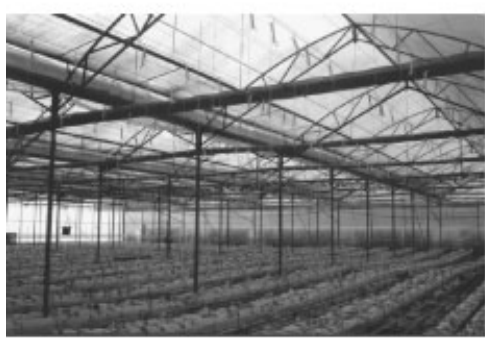

inside structure

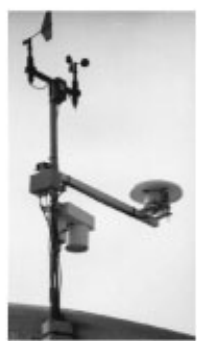

outside climate sensors

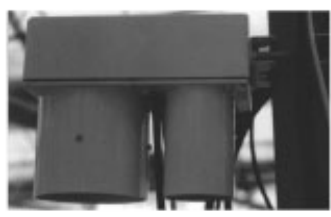

inside climate sensors

the application presented in this study, the developed and implemented algorithms are [31,32]:

- Temperature control using ventilation

1. PI control based on inside temperature

2. Gain scheduling PI control based on inside temperature and outside temperature

3. Gain scheduling PI control based on inside temperature, outside temperature, and wind speed

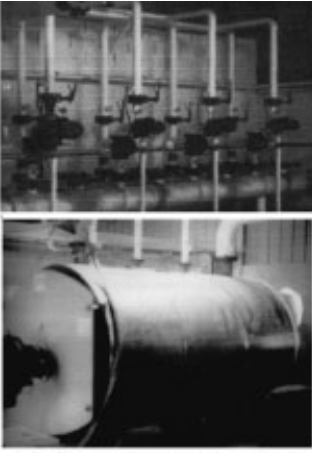

mixing valves and pumps and boiler with burner

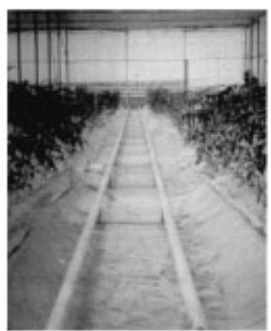

heating pipes

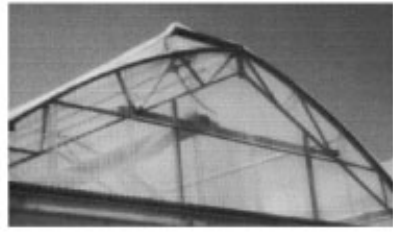

ventilation

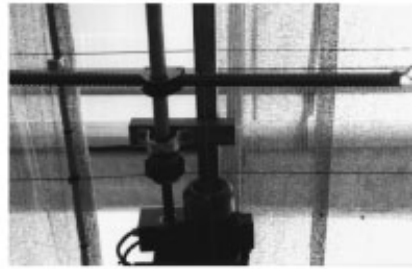

shade screen

Figure 3 Elements of greenhouse automation. 
4. Gain scheduling PI control based on inside temperature and humidity and outside temperature and wind speed

- Temperature control using heating

1. PI + antiwindup cascade control

2. Gain scheduling PI + antiwindup cascade control taking into account the influence of outlet temperature and wind speed.

- Radiation control using shade screen

1. On/off

2. On/off with dead-zone

3. On/off with delay

4. On/off with average values

5. On/off modified with values of inside temperature and humidity

- Open loop irrigation control based on schedule

A tutorial has been included in the developed web application explaining all these algorithms, although they can be found in many control textbooks and in the References [31,32].

\section{Control of Greenhouse Climate and Irrigation From a PLC}

The hardware platform used has been a Siemens Simatic S7-200, CPU 214 using the AWL language and Step 7 Microwin to program the control algorithms mentioned in the previous section. The data acquisition and control is performed through the A/D I/O boards of the PLC. As the developed tool allows selecting the control algorithm as well as to change the set points and control parameters, a part of the PLC memory has been used to read and write values from a PC (connected to the PLC through a serial portPPI communication).

\section{Control of Greenhouse Climate and Irrigation From a PC Using LabVIEW}

For developing the control algorithms in the PC hardware platform LabVIEW 6.1 has been used. Since LabVIEW is based on graphical programming, users can build instrumentation called "virtual instruments (VIs)" using software objects. The mentioned control algorithms have been developed following a hierarchical structure, thanks to the encapsulation of the algorithms into independent VIs and a library of algorithms has been implemented which stores the different algorithms for ventilation, heating, irrigation, and shade screen. Also VIs such as saturation and mean filters have been included.

The values of system's variables are obtained through a module developed in LabVIEW, independent of the final application, allowing different hardware data acquisition possibilities: PCI/ISA acquisition board, remote RS232 module, data files, and so on. Once the data have been acquired, these are passed to the control algorithms and the outputs are calculated according to set point and control parameters. These outputs enter another independent module, which sends them to the control devices. Four main control panels have been developed (Fig. 4) to control the temperature using ventilation (a) or heating (b), radiation using shade screen (c), and irrigation (d). The panels allow selecting the control algorithm from a list of implemented ones. Several active fields are also displayed for changing the set points and control parameters. Some graphs have been included to select and show the evolution of the set points, controller outputs and system outputs in real time. Regarding the panel for controlling the radiation using shade screen, there are several fields for selecting the parameters of the different alternatives of on/off control, as well as to modify the set points and parameters related with temperature and humidity. The panel devoted to control the irrigation allows selecting the irrigation time intervals (irrigation based on a schedule).

One interesting feature of the system is that the user can remotely develop his own control algorithms in C language (dll) or in LabVIEW and send them using the file transfer protocol (FTP) to test their behaviour in the system using the FTP option in the drop-down list associated. In addition to the control panels described, other different panels have been developed to display outside environmental variables.

\section{A Tool for Combining Different Hardware Platforms}

As it has been previously mentioned that one of the goals of this application is to allow the selection of the control device (PC or PLC) to fit different user needs. The solution for developing a main tool from which this selection may be performed has been based on the use of the standard Ole for process control (OPC) to allow the connection of LabVIEW with the PLC. As it is known, OPC is an industrial standard created by a large number of software and hardware suppliers in the field of automation in collaboration with Microsoft. This standard defines a set of methods that allow exchanging data between hardware systems and 


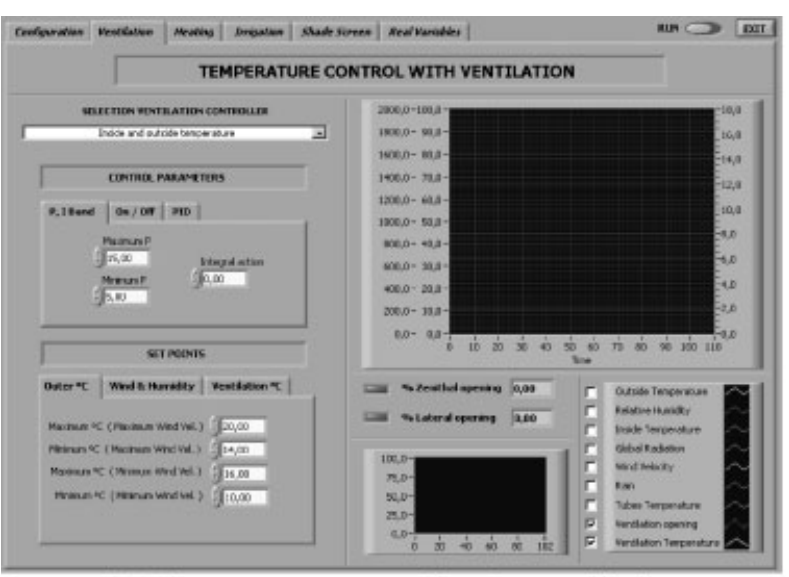

(a) Temperature control using ventilation

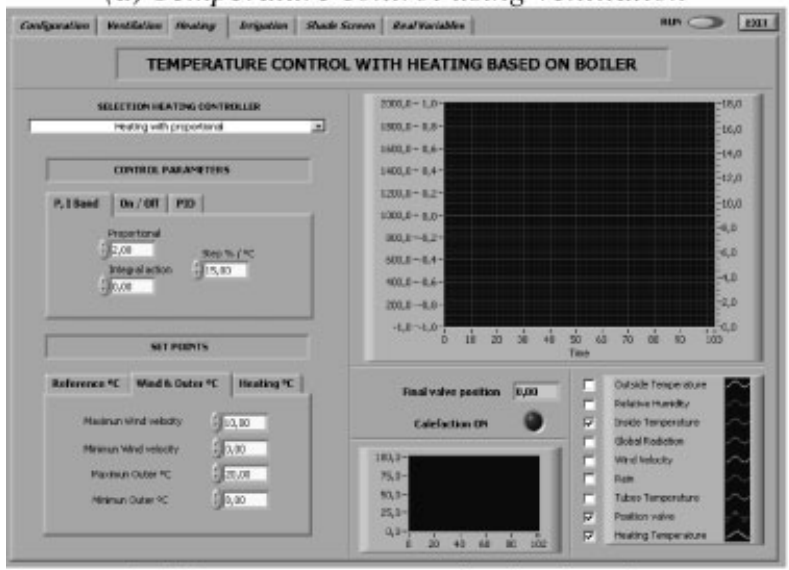

(c) Temperature control using heating

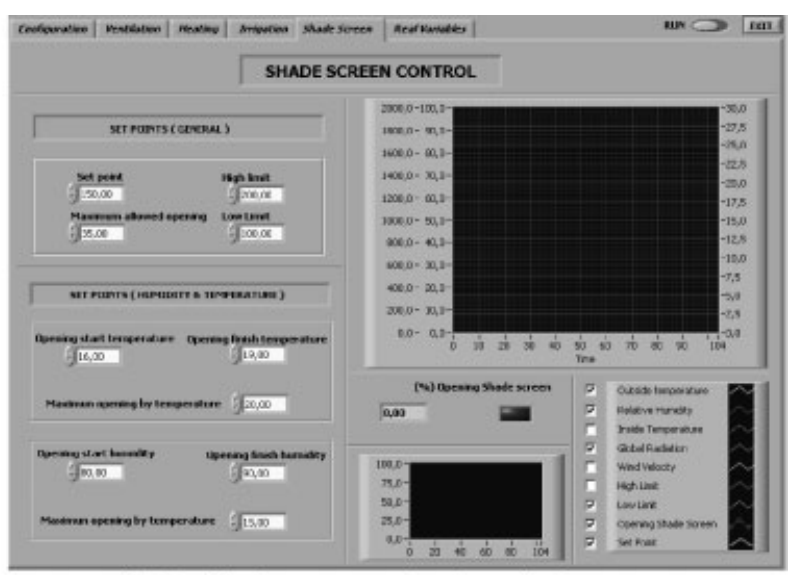

(b) Radiation control using shade screen

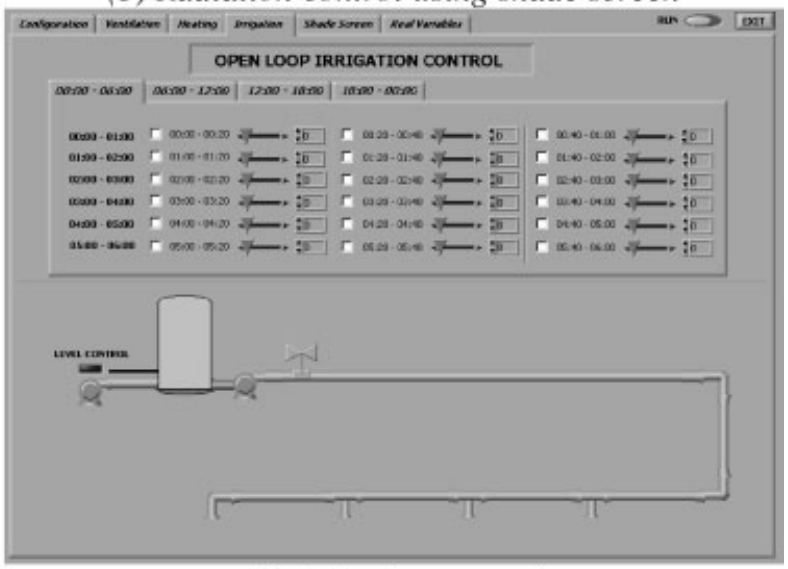

(d) Irrigation control

Figure 4 Control panels.

computers with Microsoft's operating systems. This prevents the user from developing his own interfaces and drivers depending on the hardware devices. Two elements are required to use OPC standard (Fig. 5):

- An OPC Server, which provides the set of device drivers allowing the communication between the application and the hardware.

- An OPC Client that must be included in the user application. This client communicates with the OPC server to exchange data with the device.

In this application LabVIEW has been used as OPC client, and Keepware Server (trial version) has been used as OPC server. This server has the PPI drivers for communicating with PLC.

\section{Development of the Remote Application and Incorporation to a Website}

Once that the application has been developed for local control, it is necessary to study the possible alternatives for developing the remote control lab. In

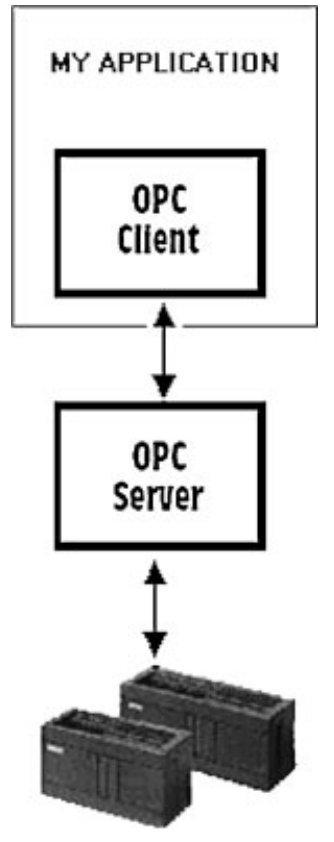

Figure 5 OPC Client-Server. 
the application shown in this study, the different alternatives are:

- CGI using Internet Toolkit of LabVIEW: it is based in the use of a set of CGIs-VIs included in the Internet toolkit for LabVIEW. This approach uses a snapshot of the control panel, mapping it and associating each mapped zone with one server CGI.

- LabVIEW virtual network computing (LabVNC): it consists of a Java applet that displays the control panel in the client computer using the well-known remote desktop technique.

- AppletVIEW: this tool is able to reconstruct a VI into a Java applet using a library of Java components, allowing to control the panel remotely.

- Datasocket JavaBean and ErgoTech: these are a couple of Java libraries which have components to allow the remote communication using datasockets, and a set of graphic components to allow the reconstruction and display of the control panel. In this case the reconstruction is not automatic.

- Remote panel control of LabVIEW 6.1: incorporated in LabVIEW 6.1, allows to remotely control the panel through the web (using ActiveX) or as a remote application.

- Other traditional implementations: other possibilities can be used to remotely control the application, such as the implementation of the communication using sockets between Java applets and a developed application with LabVIEW.
The remote panel control option has been selected after evaluating the cost and effort required for implementing all of them. With this tool, once the application has been developed with LabVIEW to perform local control, it is straightforward to incorporate it and control it through a web page (Fig. 6).

This tool allows user to control and display system variables in a remote form. As it was commented previously, it consists of an ActiveX which is accessible from a web browser, and that it contains the VI to be controlled. The web page, which contains the ActiveX must be integrated into LabVIEW web server. Thus, two servers are included in the server unit: the LabVIEW web server that contains the web page with the ActiveX would allow remote control and the Apache Web Server which contains the rest of the pages. Figure 7 shows an example of the used ActiveX.

\section{REMOTE LABORATORY}

As it has been pointed out, agriculture is one of the main economic sectors in Almería (Southeast Spain), and thus, the University of Almería has several degrees related with this field. Professional associations and engineers of many companies have also shown a keen interest in having a continuous training in the field of greenhouse automation, as this has been recently included in the academic degrees in few universities. So, it is quite important to allow engineers and technicians, both from the academic

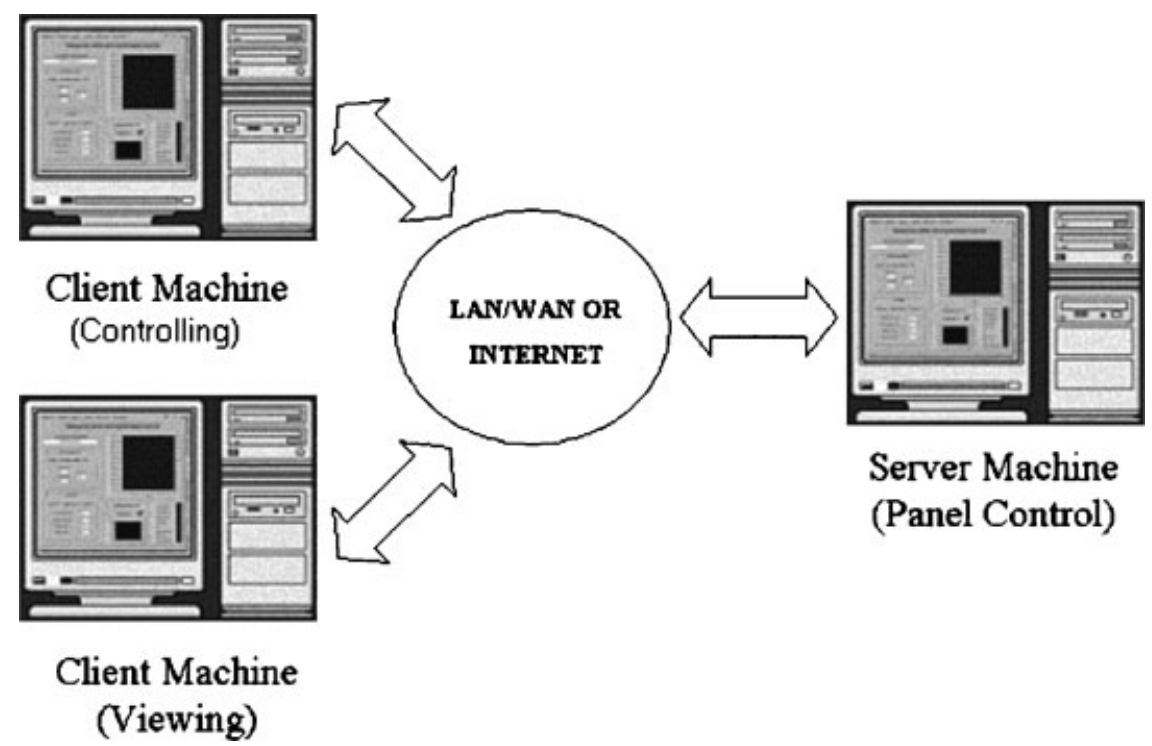

Figure 6 Remote panel control. 


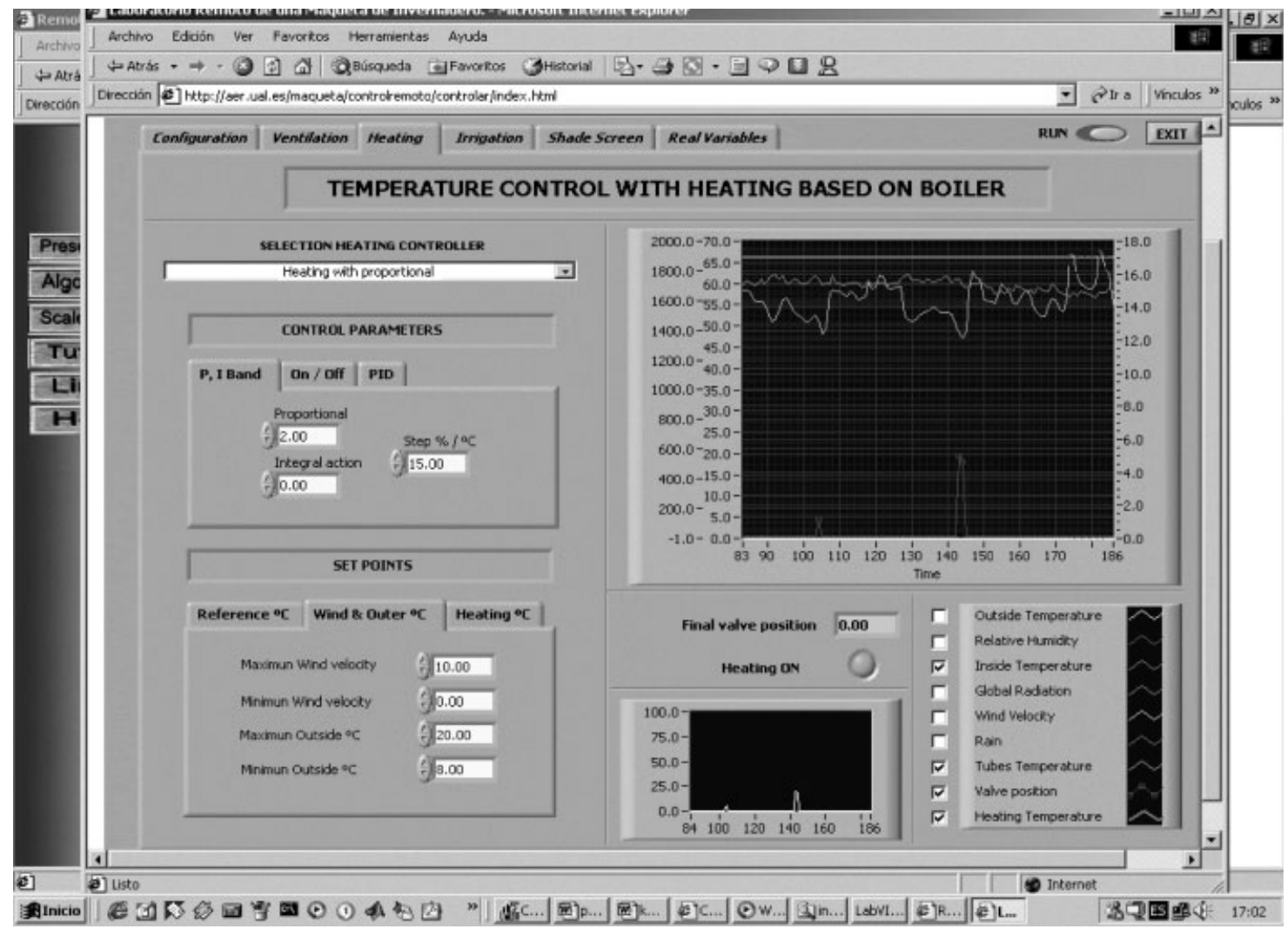

Figure 7 LabVIEW in Web with ActiveX.

and industrial fields, to have the opportunity to learn greenhouse control practice and to have the possibility to perform quasi-real tests without temporal and spatial restrictions. With this idea in mind, a greenhouse scale model (Fig. 8) was developed under the framework of the DAMOCIA project (ESPRITSpecial Action P7510 PACE) [33].

The scale model is installed at the Automatic Control, Robotics and Artificial Vision Laboratory of the University of Almería. Several sensors have been installed to measure the main variables to be controlled: inside air temperature and humidity and inside PAR radiation. An external meteorological station has been also placed to allow measuring outside temperature, global and PAR radiation, humidity, wind speed, and wind direction. The solar radiation variations are simulated by using a focus of $500 \mathrm{~W}$ placed onto the greenhouse scale model. Wind speed is also simulated
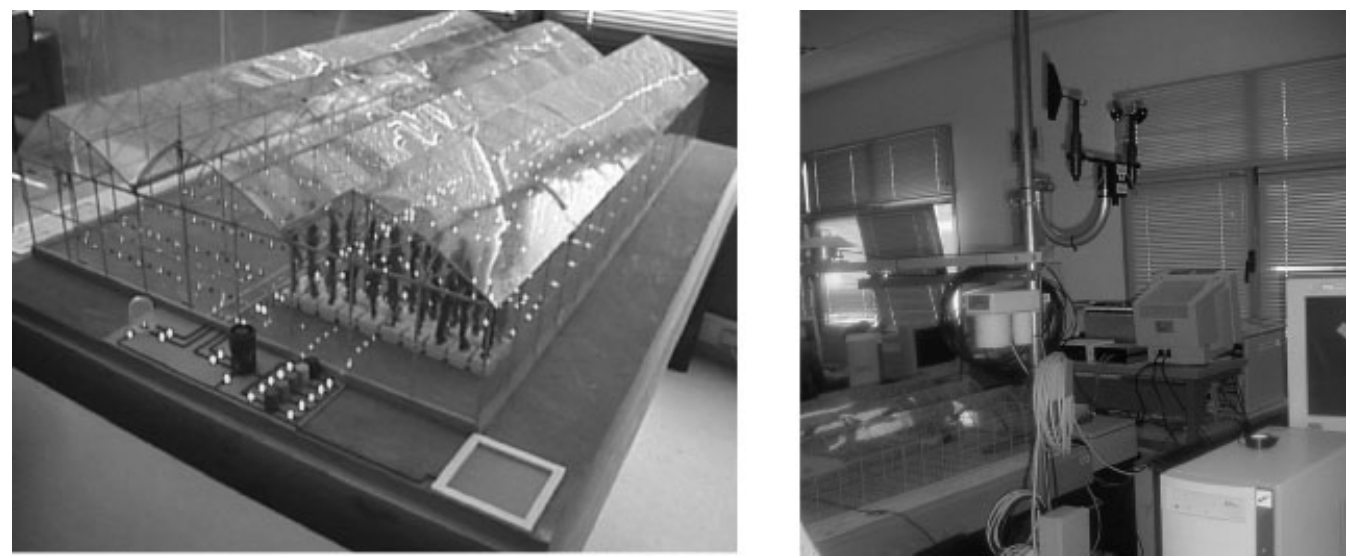

Figure 8 Greenhouse scale model and meteorological station. 
using a DC ventilator controlled by the serial port. There exists also the possibility of reading data from files obtained from the experiences in real greenhouses. From the control point of view, the scale model is provided with a natural ventilation system (with two DC motors for zenital and lateral vents aperture), a forced ventilation system (with a DC ventilator), a simulated irrigation and fertilization system (with leds), a simulated distributed pipes heating system (with leds), a heating system using resistances, and a shade screen (with one DC motor). The motors are activated using a set of relays controlled by the serial port.

Two RS232 control modules (ICPDAS company) have also been used for acquiring the data. The first module is the I-7520 and performs the conversion between RS485 protocol (modules protocol) and RS232 protocol to allow the communication with the PC. The I-7017 is the second module, which performs the data acquisition with eight analogical inputs.

An important aspect in a remote laboratory is to allow the students feeling that they are controlling a real system. One way to do this is to use visual feedback. For this reason, a video server (AXIS 2400) and two CCD cameras have been used, allowing to view the scale model remotely.
A set of web pages including automatic control theory tutorials and the explanation of control algorithms has been included. Also, the user can download the results of his experiments. For doing this, another set of web pages has been developed using the PHP language and an open source graphic library JPGraph. When an experiment is performed, two graphics and two files with the results are created.

A website for the remote laboratory (http://aer. ual.es/maqueta/) has been created, whose main page is shown in Figure 9. From this page, it is possible to access different parts of the website through a menu. The menu options are: presentation page, a set of pages with control theory, one page to access the application remotely and to view the scale model with two cameras, a tutorial page, a page with several links, and another page with the data of the authors of the remote laboratory. For accessing the application, user authentication is necessary. As an example of the application of the developed algorithms, Figure 10 shows the results obtained when controlling inside temperature with forced ventilation.

A configuration panel has been incorporated to the developed application in LabVIEW to configure new devices. This screen is shown in Figure 11 and allows modifying data acquisition source (file or

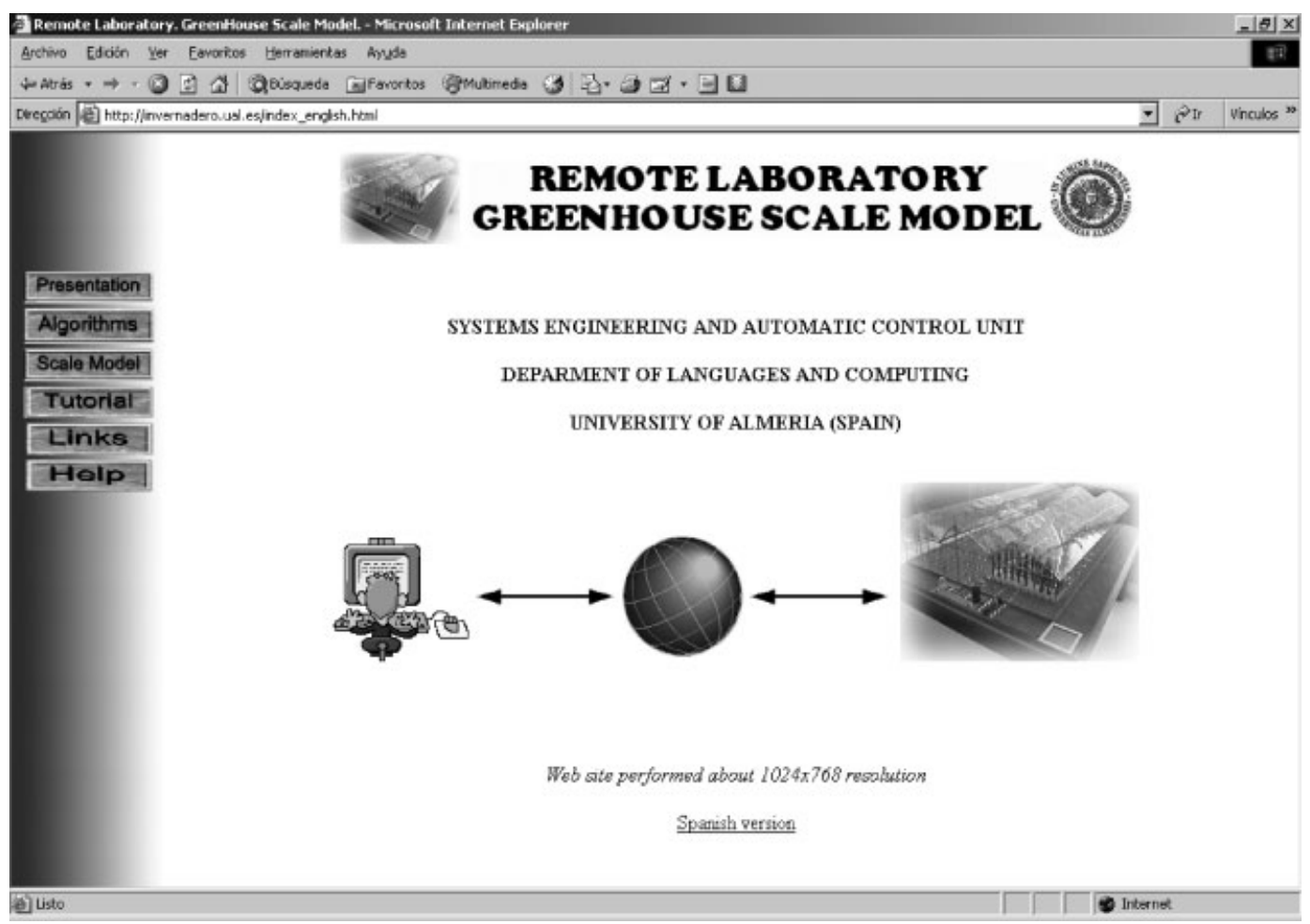

Figure 9 Website. 


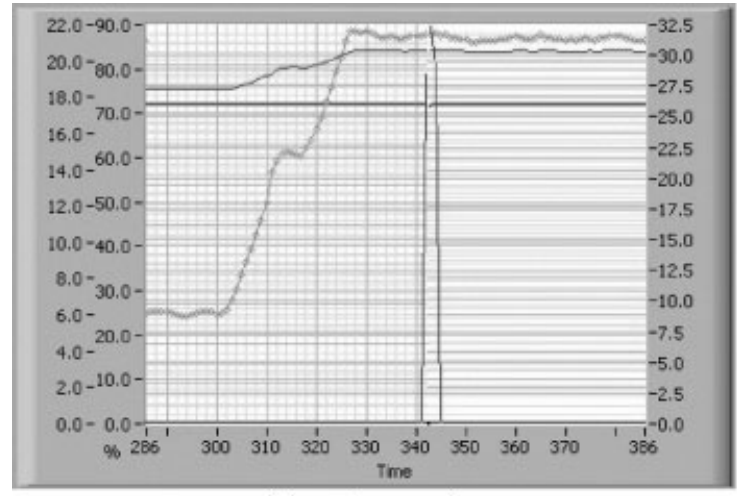

(a) vents opening

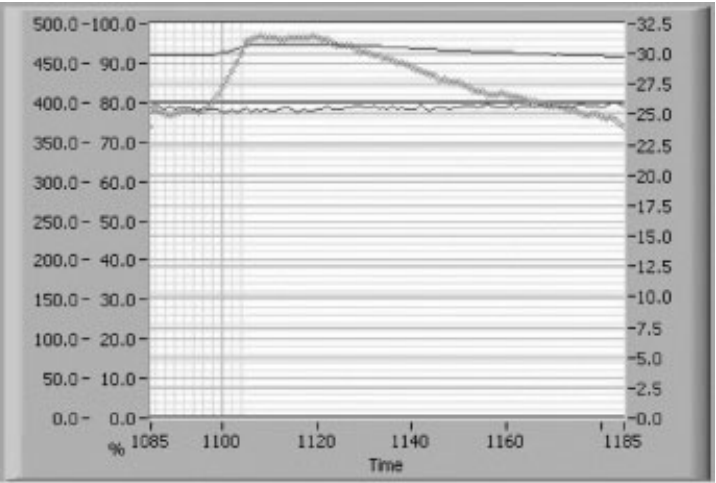

(b) vents closing

Figure 10 Examples of temperature control with ventilation.

sensor), the sampling period, the control device (PC or PLC), the controllers to use (temperature, irrigation, and humidity), and the serial ports configuration for controlling and data acquisition (only accessible by the administrator).

\section{STEPS TO PERFORM A REMOTE TEST}

The steps to perform an exercise using the remote lab are briefly explained in what follows:
1. Connect to the website. The presentation page shown in Figure 9 appears.

2. Select Algorithms option in the left page menu to remind the underlying theory.

3. Read the tool Tutorial for learning how to use the remote application.

4. Ask for the username and password to the remote lab responsible to access to the scale model.

5. Go into the Scale Model option in the menu and introduce username and password.

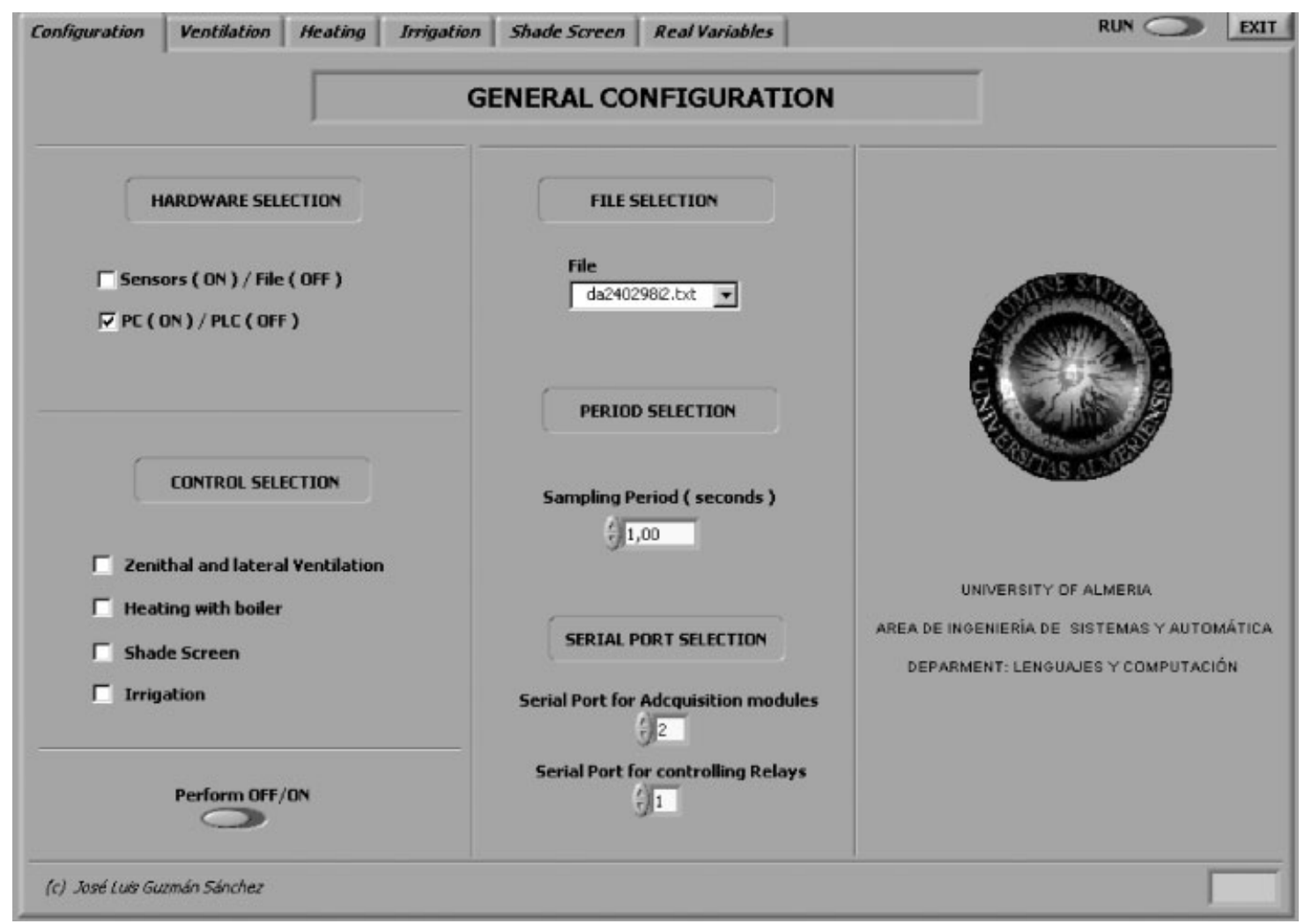

Figure 11 Configuration panel. 
6. Use the tool following the steps shown in the tutorial (step 3). The students may begin using the control algorithms included in the tool. After this they can develop their own algorithms in C language (dll) or in LabVIEW and send them using FTP to test their behaviour.

7. Select (optional) visual feedback using CCD cameras to see the results remotely.

8. At the end of the tests, a web page with graphical and text results is automatically created.

\section{CONCLUSIONS}

Thanks to the advances in the ICT, many teaching tools are being developed that allows to improve the educational methods. Part of these tools belongs to the distance education and telelaboratories fields. These new teaching tools allow the students to work at any time and anywhere and to be self-sufficient. In this study, we presented a system able of remotely controlling greenhouse climatic conditions and irrigation using different hardware and software platforms. These platforms are among the main aspects of modern agriculture and emerging disciplines at universities. The system has been used to develop a remote laboratory that offers the students the possibility of having remote control of a greenhouse scale model.

\section{ACKNOWLEDGMENTS}

The authors acknowledge CICYT (projects QUI990663-C02-02, DPI2001-1012, DPI2001-2380-C02-02 and DPI2002-04375-C03-03) for partially funding this work.

\section{REFERENCES}

[1] S. Dormido, Control learning: Present and future, IFAC Annual Control Reviews, Elsevier, New York, Vol. 28, 2004, pp 115-136.

[2] S. E. Poindexter and B. S. Heck, Using the web in your courses: What can you do? What should you do? IEEE Control Syst Mag 19 (1999), 83-92.

[3] R. M. Powell, H. Anderson, J. Van Der Spiegel, and D. P. Pope, Using web-based technology in laboratory instruction to reduce costs, Comput Appl Eng Educ 10 (2002), 204-214.
[4] D. Srinivasagupta and J. Babu, An Internet-mediated process control laboratory, IEEE Control Syst Mag 23 (2003), 11-18.

[5] M. L. Corradini, G. Ippoliti, T. Leo, and S. Longhi, An Internet based laboratory for control education. Proceedings of the 40th IEEE Conference on Decision and Control, 3, Orlando, FL, 2001, pp 2833-2838.

[6] R. Arnaz, M. A. Pachesco, A. Mendoza, J. Bernardez, and J. R. Perán, Development of a distant ac motor laboratory. IFAC 15th Triennial World Congress, Barcelona, Spain, 2002.

[7] M. Casinim, D. Pratticizzo, and A. Vicino, The automatic control Telelab: A remote control engineering laboratory. Proceedings of the 40th IEEE Conference on Decision and Control, 4, Orlando, FL, 2001, pp 3242-3247.

[8] J. L. Guzmán, J. F. Sarabia, F. Rodríguez, J. C. Moreno, and M. Berenguel, Entorno para programación remota de robots manipuladores en ACL con realimentación visual. EIWISA'02, Alicante, Spain, 2002.

[9] J. C. Moreno, M. Berenguel, F. Rodríguez, J. F. Sarabia, R. Garrote, J. L. Guzmán, and O. López, Proyecto de aplicación de telerrobótica a un mini-robot móvil. EIWISA'01, UNED, Madrid, Spain, 2001.

[10] X. F. Yuan and J. G. Teng, Interactive web-based package for computer-aided learning of structural behavior, Comput Appl Eng Educ 10 (2002), 121-136.

[11] H. Jiang, Y. C. Kurama, and D. A. Fanella, WWWbased virtual laboratories for reinforced concrete education, Comput Appl Eng Educ 10 (2002), 1-5.

[12] S-C Ou, W-T Sung, S-J Hsiao, K-C Fan, Interactive web-based training tool for $\mathrm{CAD}$ in a virtual environment, Comput Appl in Eng Educ 10 (2002), 182-193.

[13] P. S. Shiakolas, V. Chandra, and J. Kebrle, Environment for engineering design, analysis and simulation for education using MATLAB via the World Wide Web. I. Environment description and development, Comput Appl Eng Educ 10 (2002), 99-108.

[14] P. S. Shiakolas, V. Chandra, J. Kebrle, and D. Wilhite, Environment for engineering design, analysis and simulation for education using Matlab via the World Wide Web. II. Representative examples-System simulation and planar mechanism synthesis and analysis, Comput Appl Eng Educ 10 (2002), 109-120.

[15] S. K. Ong and M. A. Mannan, Development of an interactive multimedia teaching package for a course on metalworking, Comput Appl Eng Educ 10 (2002), $215-228$.

[16] N. M. Avouris, N. Tselios, and E. C. Tatakis, Development and evaluation of a computer-based laboratory teaching tool, Comput Appl Eng Educ 9 (2001), 8-19.

[17] S. H. Huang, Q. Su, N. Samant, and I. Khan, Development of a Web-based integrated manufacturing laboratory, Comput Appl Eng Educ 9 (2001), 228-237. 
[18] T. Murphy, V. G. Gomes, and J. A. Romagnoli, Faciliting process control teaching and learning in a virtual laboratory environment, Comput Appl Eng Educ 10 (2002), 79-87.

[19] C. Schmid, The virtual control Lab VCLab for education on the web. Proceedings of the American Control Conference, 2, Philadelphia, PA, June 1998, pp 1314-1318.

[20] J. Sánchez, F. Morilla, S. Dormido, J. Aranda, and P. Ruipérez, Virtual and remote control labs using Java: A qualitative approach, IEEE Control Syst Mag 22(2) (2002), 8-20.

[21] A. Borges, M. Perez, and F. Ramirez, A graphical interface to link virtual instruments through a Web Browser. Proceedings of the XIII Brazilian Symposium on Computer Graphics and Image Processing, IEEE, 2000, pp 354.

[22] S. P. Liou, H. Soelaeman, and P. Leung, Distance learning power engineering laboratory, IEEE Comput Appl Power Syst 12 (1999), 51-56.

[23] LabVIEW Distance Learning Solution Guide. National instruments. http://ni.com/pdf/academic/distance $\backslash$ learning.pdf

[24] X. Vilalta, D. Gillet, and C. Salzmann, Contribution of the definition of best practices for the implementation of remote experimentation solutions. IFAC Workshop on Internet Based Control, IFAC Workshop on Internet Based Control Education, IBCE'01, Madrid, Spain, December 12-14, 2001.

[25] C. Schuguresnsky, R. Fullana, S. Lapilli, J. Pucheta, and A. Guzmán, Invernadero experimental para validación de algoritmos. Instituto de Automática, Facutltad de Ingeniería, Universidad Nacional de San Juan, Argentina. XVII Congreso Argentino de Control Automático, AADECA, Buenos Aires, Argentina, September 2000.

\section{BIOGRAPHIES}

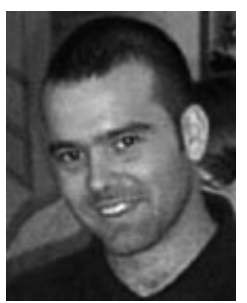

José Luis Guzmán received his degree in computer science engineering in 2002 from the University of Almería (Spain), where he is a researcher and member of the Automatic Control, Electronics and Robotics group. $\mathrm{He}$ is currently working towards his $\mathrm{PhD}$ in the field of control education and robust model predictive control techniques with applications to interactive tools, virtual and remote labs, and agricultural processes.
[26] C. M. J. Alves-Serodio, J. L. Monteiro, and C. A. C. Couto, An integrated network for agricultural management applications. Proceedings ISIE'98. IEEE International Symposium on Industrial Electronics, Vol. 2, 1998, pp 679-683.

[27] C. M. J. A. Serodio, P. M. M. A. Silva, C. A. C. Couto, and J. L. Monteiro, Embedded Java in agricultural control systems. Industrial Electronics Society, 1999, IECON'99 Proceedings, The 25th Annual Conference of the IEEE, Vol. 2, 1999, pp 716-721.

[28] C. Ramos, J. M. Herrero, M. Martínez, and X. Blasco, Internet en el desarrollo de prácticas no presenciales con procesos industriales. EIWISA'01, UNED, Madrid, Spain, 2001.

[29] G. Novak, E. T. Patterson, A. D. Gavrin, and W. Christina, Just-in-time teaching: Blending active learning with web technology, Prentice Hall, Englewood Cliffs, NJ, 1999.

[30] J. Sánchez, Un nuevo enfoque metodológico para la enseñanza a distancia de asignaturas experimentales: análisis, diseño y desarrollo de un laboratorio virtual y remoto para el estudio de la Automática a través de Internet. PhD Thesis, UNED, Spain, 2001.

[31] F. Rodríguez, Modelling and hierarchical control of greenhouse crop production. PhD Thesis, University of Almería, Spain, 2002.

[32] P. G. H Kamp and G. J. Timmerman, Computerized environmental control in greenhouses. IPC Plant, Ede, The Netherlands, 1996.

[33] F. Rodríguez, A. Corral, M. Berenguel, and F. Bienvenido, Application scale model for teaching automatic control of the greenhouse climate and irrigation tasks. 2nd European Conference for Information Technology in Agriculture EFITA99, Bonn, Germany, 1999, pp 795-805.

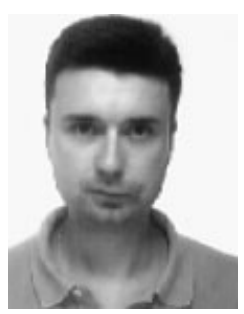

Manuel Berenguel is an associate professor of systems engineering and automatic control and is responsible for the Automatic Control, Electronics and Robotics group at the University of Almería, Spain. He earned the industrial engineering degree and $\mathrm{PhD}$ from the University of Seville (Spain), where he received an award for the best engineering thesis of the year and was researcher and associate professor for 6 years. His research interests are in the fields of predictive, adaptive, and robust control, with applications to solar energy systems, agriculture, and biotechnology. He has been a reviewer for several journals and has authored and coauthored more than 50 technical papers for international journals and conferences. He is coauthor of the book Advanced Control of Solar Plants, published by Springer in 1997. 


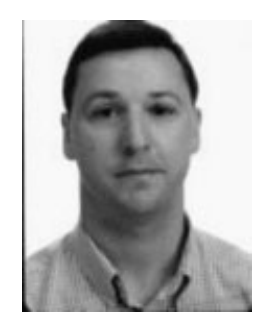

Francisco Rodríguez is an associate professor of systems engineering and automatic control at the University of Almería (Spain). He received a degree in telecommunications engineering from Madrid Polytechnic University (Spain) and his $\mathrm{PhD}$ degree, in 2002, from the University of Almería. Now he is a researcher and member of the Automatic Control, Electronics and Robotics group of the University of Almería. His scientific interests are focused on the application of modeling, automatic control, and robotics techniques to agricultural systems and education.

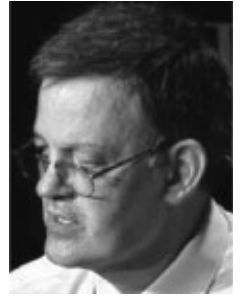

Sebastián Dormido received a degree in physics from Madrid Complutense University in 1968 and earned his $\mathrm{PhD}$ degree with a thesis on adaptive sampling from the University of the Basque Country, Spain, in 1971. In 1981, he was appointed a full professor of control engineering at UNED Faculty of Sciences. Since 1986 he has been head of UNED Department of Computer Sciences and Automatic Control. His scientific activity is in various areas of the control engineering field: computer control of industrial processes, adaptive systems, model-based predictive control, robust control, and modeling and simulation of continuous processes. 